\title{
How epicardial U-wave changes are reflected in body surface precordial electrocardiograms in anterior or inferoposterior myocardial ischaemia during coronary angioplasty
}

\author{
H Kataoka, S Yano, A Tamura, Y Mikuriya
}

\begin{abstract}
Objectives-To examine the epicardial Uwave changes recorded in intracoronary electrocardigrams (ECGs) during anterior or inferoposterior myocardial ischaemia and the corresponding changes in precordial ECGs recorded from the body surface in humans.

Methods-40 patients undergoing coronary angioplasty of the left anterior descending (LAD) coronary artery (22 patients) or left circumflex (LC) artery (18 patients). Intracoronary and surface precordial ECGs were simultaneously recorded under baseline conditions and during angioplasty.
\end{abstract}

Results-Four different patterns of $\mathbf{U}$ wave change were identified on the intracoronary ECG: change to positivity, no change, change to negativity, and biphasic change. The incidence of each pattern was similar in the two groups (LAD $v$ LC groups, $23 \% v$ v 39\%; $23 \%$ v 17\%; $41 \% v$ $44 \% ; 13 \% v 0 \%$, respectively). The intracoronary ECG was more sensitive than the surface ECG for detecting U-wave changes (intracoronary $v$ surface ECG: LAD group, $77 \%$ v 55\%; LC group, $83 \%$ v $28 \%$ ). A study of the correlation between intracoronary and surface precordial ECGs showed that in patients who had Uwave changes in their intracoronary ECG (17 LAD and 15 LC patients) $65 \%$ of the LAD group but only $6 \%$ of the LC group had primary $U$-wave changes in the surface precordial ECG, and that $27 \%$ of the LC patients had reciprocal U-wave changes in the right to central precordial ECG.

Conclusions-These results provide fundamental information for an understanding of the correlation between $U$-wave changes in the epicardial and surface precordial ECGs during myocardial ischaemia in humans. As well as the primary $U$-wave changes seen in many of those with anterior myocardial ischaemia, some of those with posterior myocardial ischaemia had reciprocal $U$ wave changes in their surface precordial ECGs.

(Heart 1996;76:397-405)

Keywords: electrocardiogram; U wave; myocardial ischaemia; angioplasty
Many published reports describe the association between inverted U-waves and myocardial ischaemia. ${ }^{1-10}$ Several of these studies have suggested that a negative $U$-wave in the precordial leads in a body surface electrocardiogram (ECG) at rest $^{4}$ or during exercise testing, ${ }^{3}$ variant anginal attacks, ${ }^{6-9}$ or coronary angioplasty ${ }^{10}$ is a moderately sensitive, but highly specific, indicator of the presence of anterior myocardial ischaemia. Recently, some reports ${ }^{11-13}$ have described the phenomenon of a reciprocal positive $U$-wave change in the body surface precordial leads in inferoposterior myocardial ischaemia. Another report described a positive epicardial U-wave change during angioplasty-induced myocardial ischaemia in humans. ${ }^{14}$ Thus questions remain about the clinical meaning of U-wave changes in response to myocardial ischaemia. A better understanding of the clinical implications of body surface U-wave changes during myocardial ischaemia may be obtained by studying the correlation between U-waves in epicardial and body surface ECGs. However, clinical information about epicardial U-wave changes during myocardial ischaemia is limited, ${ }^{14}$ and there are no studies of the correlation in humans.

Because the tip of the guide wire used for coronary angioplasty lies close to the lesion and transmits electrical signals it can be used to record epicardial ECGs. ${ }^{15-17}$ An intracoronary ECG recorded in this way has the advantage of being taken near myocardium supplied by the artery undergoing angioplasty. In the present study we examined U-wave changes in the intracoronary ECG during angioplasty of the left anterior descending (LAD) or left circumflex (LC) coronary artery and correlated these with U-wave changes recorded by the precordial leads of body surface ECGs. The design of this study provides a model of sudden coronary artery occlusion, which can be used to assess the U-wave changes that occur within the first minutes of coronary occlusion.

\section{Patients and methods}

PATIENTS

We prospectively studied 54 patients with coronary artery disease who were undergoing percutaneous transluminal coronary angioplasty of the LAD or LC coronary artery at our institution. Informed consent was obtained before the procedure. Patients with complicating major heart disease (other than coronary artery disease) were not included in 
Table 1 Intracoronary and body surface ECG findings in the 22 study patients undergoing LAD coronary artery angioplasty

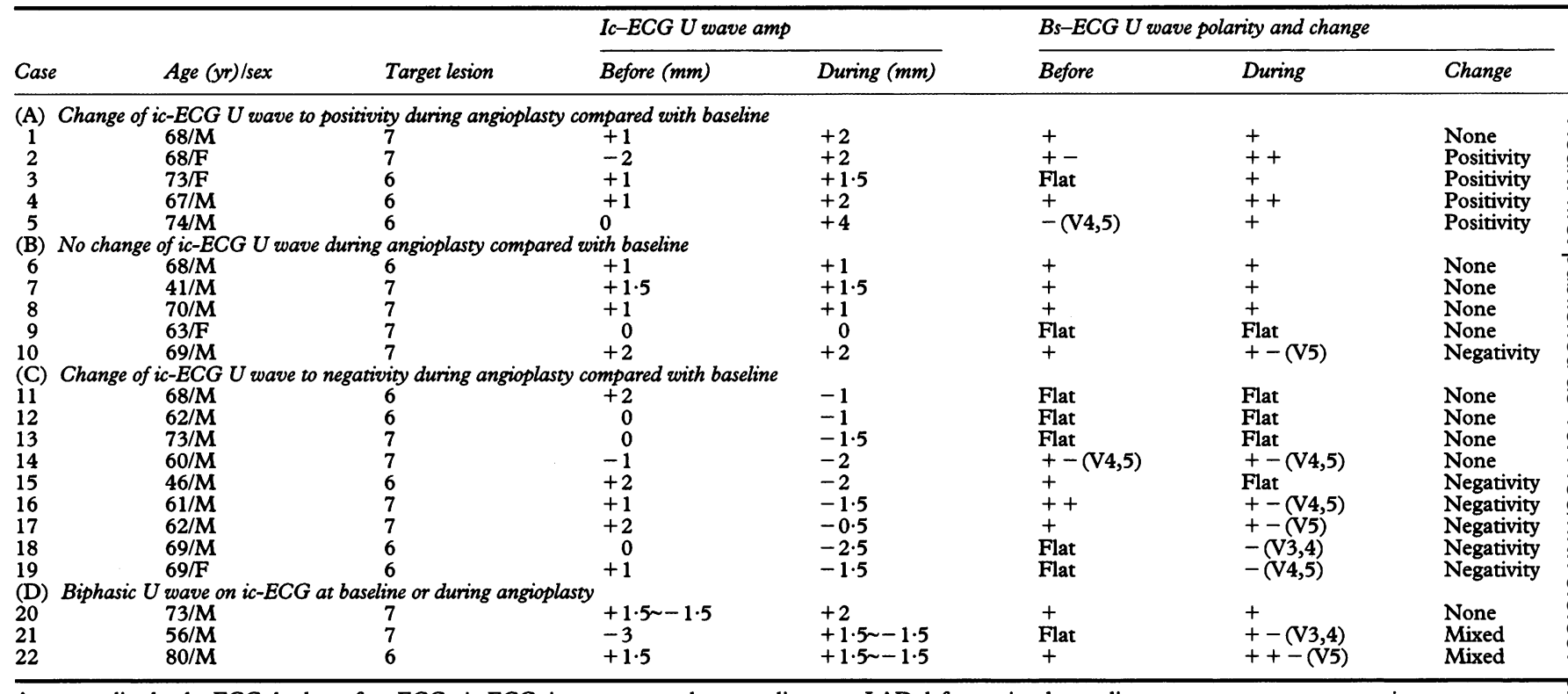

Amp, amplitude; bs-ECG, body surface ECG; ic-ECG, intracoronary electrocardiogram; LAD, left anterior descending coronary artery; mx, maximum. Polarity and relative change of U waves on the body surface ECG is shown as: -, negative deflection; + - , coexistence of negative and positive deflections; + , positive deflection; ++ , more positive deflection compared with $(+)$

Precordial lead number in parentheses indicates the leads from which negative deflection of $U$ wave was recorded.

the study. Those with complete bundle branch block, Wolff-Parkinson-White syndrome, or atrial fibrillation were also excluded. All patients were receiving antianginal medication, but none was receiving digoxin or antiarrhythmic agents during the study.

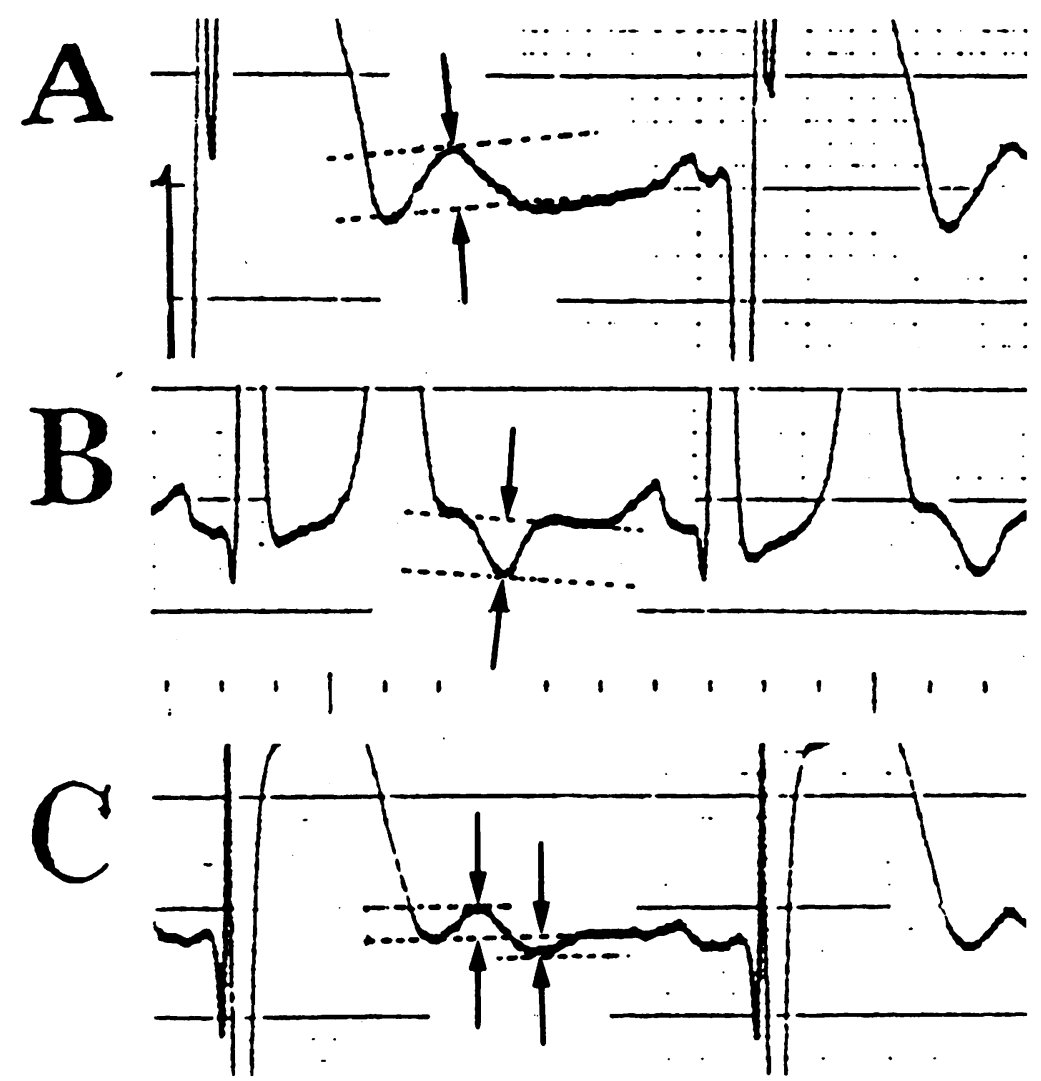

Figure 1 Three patterns of $U$ waves observed in the intracoronary electrocardiogram (ECG) and the measurement of their amplitude: $(A)$ monophasic positive $U$ wave, $(B)$ monophasic negative $U$ wave, and $(C)$ biphasic $U$ wave. Distance between arrows indicates the amplitude of the $U$ wave. In biphasic $U$ waves the point of reversal of polarity is selected as the point of separation into positive and negative portions, with each portion measured separately.
CORONARY ANGIOPLASTY AND ECG RECORDING

All patients underwent coronary and left ventricular angiography before their scheduled coronary angioplasty. A significant coronary stenosis was defined as an obstruction of $\geqslant 75 \%$ of the luminal diameter. The angiographic data were interpreted by two experienced angiographers using the criteria proposed by the American Heart Association. ${ }^{18}$ Because the procedures of coronary angioplasty and recording the intracoronary ECG have been reported in detail previously, ${ }^{15-17}$ they are described only briefly here. The guiding catheter for balloon angioplasty was inserted in the usual manner, using the Judkins technique. After identification of the target lesion by angiography a 0.014 inch $(0.036 \mathrm{~cm})$ diameter, high-torque, flexible, steerable guide wire (Hi-Per Flex, USCI, New Jersey, USA) was advanced through the lesion, and the tip was positioned at the distal coronary artery. The shaft of the guidewire was coated with Teflon, leaving only the distal $30 \mathrm{~cm}$ uninsulated. The proximal end of the guidewire was connected to the V6 lead of a standard electrocardiograph to record a local unipolar intracoronary ECG from the myocardium, distal to the stenosis which was to be dilated. Body surface ECGs at paper speed of $25 \mathrm{~mm} / \mathrm{s}$ and sensitivity of $1 \mathrm{mV} / 10$ $\mathrm{mm}$ were recorded regularly, simultaneously with intracoronary ECGs, using a six-channel standard 12 lead electrocardiograph (Electrocardiograph Cardiofax V, Nihon-Kohden, Tokyo, Japan) at baseline and at 20-30 s intervals during balloon inflation. The number and duration of each inflation and the pressure used were determined by the operator, based on the angiographic appearance of the blood vessel before and after each inflation. 
Table 1 continued

\begin{tabular}{|c|c|c|c|c|c|}
\hline \multicolumn{2}{|c|}{$I c-E C G S T$ shift } & \multicolumn{3}{|c|}{ Bs-ECG $m x S T$ shift } & \multirow[b]{2}{*}{ Projection index of $S T$ shift } \\
\hline Before ( $\mathrm{mm}$ ) & During (mm) & Lead & Before (mm) & During (mm) & \\
\hline $\begin{array}{l}4 \\
0 \\
1 \\
2 \\
0\end{array}$ & $\begin{array}{c}11 \\
8 \cdot 5 \\
14 \cdot 5 \\
10 \\
11\end{array}$ & $\begin{array}{l}\text { V3 } \\
\text { V3 } \\
\text { V4 } \\
\text { V3 } \\
\text { V3 }\end{array}$ & $\begin{array}{l}2 \\
0 \\
0 \\
1 \cdot 5 \\
0\end{array}$ & $\begin{array}{l}5 \\
7 \cdot 5 \\
7 \\
4 \\
5\end{array}$ & $\begin{array}{l}0.43 \\
0.88 \\
0.52 \\
0.31 \\
0.45\end{array}$ \\
\hline $\begin{array}{l}1 \cdot 5 \\
0 \\
2 \\
0 \\
2\end{array}$ & $\begin{array}{l}9 \\
7 \\
6 \\
4 \\
4\end{array}$ & $\begin{array}{l}\text { V3 } \\
\text { V4 } \\
\text { V3 } \\
\text { V2 } \\
\text { V3 }\end{array}$ & $\begin{array}{l}0 \\
0 \\
0.5 \\
0.5 \\
0.5\end{array}$ & $\begin{array}{l}2 \\
2 \\
1.5 \\
1.5 \\
1.5\end{array}$ & $\begin{array}{l}0.27 \\
0.29 \\
0.25 \\
0.25 \\
0.50\end{array}$ \\
\hline $\begin{array}{r}2 \\
0 \\
2 \\
-2 \\
-1 \\
0 \\
0 \\
0 \\
0\end{array}$ & $\begin{array}{c}13 \\
12 \cdot 5 \\
12 \\
-10 \\
12 \\
10 \cdot 5 \\
3 \\
2 \\
4\end{array}$ & $\begin{array}{l}\text { V4 } \\
\text { V3 } \\
\text { V3 } \\
\text { V3 } \\
\text { V3 } \\
\text { V4 } \\
\text { V2 } \\
\text { V2 } \\
\text { V3 }\end{array}$ & $\begin{array}{l}0 \\
0 \\
1 \\
0 \\
1 \cdot 5 \\
0 \\
0 \cdot 5 \\
0 \cdot 5 \\
0\end{array}$ & $\begin{array}{l}3 \\
2 \\
4 \\
-3 \\
7 \\
7 \\
1 \cdot 5 \\
2 \\
2.5\end{array}$ & $\begin{array}{l}0.27 \\
0.16 \\
0.30 \\
0.38 \\
0.42 \\
0.67 \\
0.33 \\
0.75 \\
0.63\end{array}$ \\
\hline $\begin{array}{l}2 \\
0 \\
0\end{array}$ & $\begin{array}{l}13 \\
17 \\
8.5\end{array}$ & $\begin{array}{l}\text { V3 } \\
\text { V3 } \\
\text { V2 }\end{array}$ & $\begin{array}{l}0 \\
0 \\
0.5\end{array}$ & $\begin{array}{l}8 \\
4 \cdot 5 \\
2\end{array}$ & $\begin{array}{l}0.72 \\
0.26 \\
0.18\end{array}$ \\
\hline
\end{tabular}

ECG RECORDS FOR ANALYSIS

Insertion of the steerable guidewire or passage of the balloon catheter through the lesion before inflation was often enough to induce myocardial ischaemia, thus producing an ST segment shift on the intracoronary ECG at baseline.$^{19}$ In order to obtain a baseline ECG recording under conditions as free from ischaemia as possible, an ECG recording showing the minimum ST segment shift on the baseline intracoronary ECG was chosen for analysis from those obtained during several trials of angioplasty on each patient. In the selected recording we evaluated the baseline ECG strip and the strip that showed maximum ST segment elevation or depression on the intracoronary ECG (recorded during angioplasty). In one patient, who showed no ST deviation on the intracoronary ECG during the procedure, the last ECG strip recorded during coronary occlusion was chosen. All ECGs from each patient were interpreted by two independent investigators who had no knowledge of the coronary angiographic data. When there was disagreement on the interpretation of an ECG recording, a third observer evaluated the tracing in question and the findings of the majority prevailed.

ANALYSIS OF U WAVES

Clear demonstration of $U$ waves requires plotting of both the QT and the PR intervals ${ }^{20}$ to avoid confusing the deflection of the $U$ wave with the terminal $\mathrm{T}$ wave or early portion of the $P$ wave. This was done by measuring the QT and PR intervals simultaneously from the body surface limb leads, thus providing a reference for TP interval determination in the body surface precordial and intracoronary ECGs. If the QT or PR interval could not be determined accurately the patients was excluded from this study.

On the intracoronary ECGs $U$ waves were classified as three patterns on the basis of their appearance-that is, monophasic positive or negative and biphasic. We measured $U$ wave amplitude over several cycles with callipers and a hand magnifying lens as shown in fig 1 , to the nearest $0.5 \mathrm{~mm}$, using the TP segment as the isoelectric line. Four different patterns of U-wave changes from baseline to coronary occlusion were identified on the intracoronary ECGs: (1) directional change of $U$ waves in the positive direction, (2) no change, (3) directional change of $U$ waves in the negative direction, and (4) biphasic $U$ waves at baseline or during angioplasty.

In the surface precordial ECGs the $U$ waves were evaluated qualitatively because of their small amplitude. U-wave analysis in body surface EGGs included observation of the polarity and of directional changes of U-wave amplitude during the procedure. ECG recordings made at baseline and during coronary occlusion were arranged side by side and the orientation and amplitude in each precordial lead were compared. A negative $U$ wave was identified if there was a discrete negative deflection within the TP segment and a positive $U$ wave was identified if there was a discrete positive deflection. Four different patterns of directional U-wave change were distinguishable in recordings from the precordial leads made at baseline and under angioplasty-induced ischaemia: (1) directional change in the positive direction-that is, a combination of an increase in positivity, the appearance of a new positive $U$ wave, a decrease in negativity, and disappearance of a negative $U$ wave; (2) unchanged; (3) directional change in the negative direction-that is, combination of an increase in negativity, the appearance of a new negative $U$ wave, a decrease in positivity, and disappearance of a positive U wave; and (4) mixed change-that is, some precordial leads showing a directional 
Table 2 Intracoronary and body surface ECG findings in the 18 study patients undergoing $L C$ angioplasty

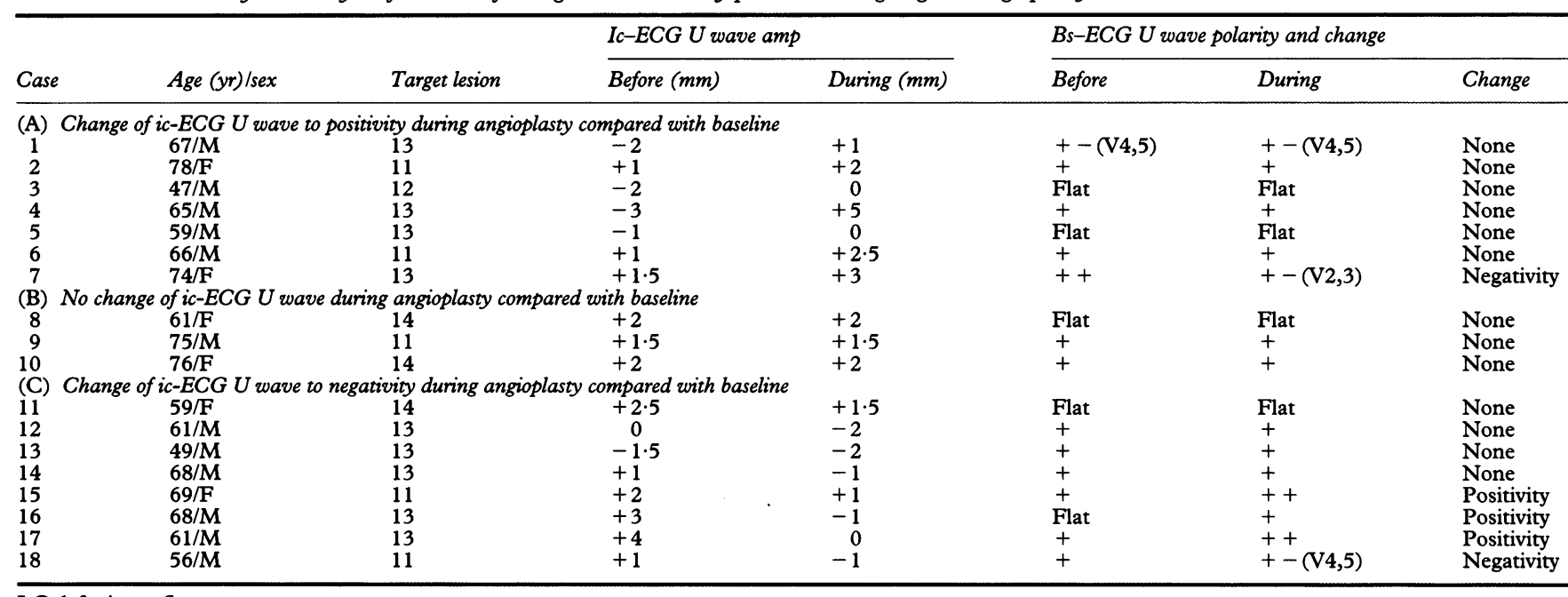

LC, left circumflex coronary artery.

See footnote to table 1 for other abbreviations.

change in the positive direction and others in the negative direction.

\section{ANALYSIS OF ST SEGMENT}

The maximal ST segment change at the J point was measured on both the intracoronary and surface precordial ECG recordings to the nearest $0.5 \mathrm{~mm}$, using the PQ segment as the isoelectric line. To clarify how the ischaemic injury in specific myocardial areas affected the body surface ECG, the ratio of the maximum ST segment change (the difference in ST level between baseline conditions and at angioplasty) on ECG recordings made from the precordial leads to that made on intracoronary ECG recordings was calculated and defined as the projection index of the ST segment.

\section{STATISTICAL ANALYSIS}

Data were recorded as means (SD). Statistical analyses were performed by Student's paired $t$ test to compare results within a group, by unpaired tests for intergroup comparisons, and by Fisher's exact probability test for discrete data. Differences were considered significant at $\mathrm{P}<0.05$.

\section{Results}

Data from 17 of the 57 patients who underwent recordings of intracoronary and body surface ECGs during the procedure were discarded because the ECGs were inadequate for analysis of $U$ waves. The main reasons for poor data included baseline drift (six patients), sinus tachycardia (three), fusion of the $T$ and $U$ waves (three), and difficulty in identifying the TP segment (five). Therefore, we report data for 40 patients ( 30 men and ten women; aged 41-80): 22 had dilatation of the LAD coronary artery and 18 had dilatation of the LC coronary artery. The site of the lesion dilated by angioplasty and ECG data for both groups are summarised in tables 1 and 2, respectively. During dilatation of the coronary artery 31 patients $(78 \%)$ developed chest pain.
CLINICAL FEATURES

In the LAD group nine patients had had a prior anterior myocardial infarction and two had abnormal $Q$ waves on the surface precordial ECG. Other patients had chronic stable angina. In the LC group, eight patients had had a prior inferior myocardial infarction. Of these, four had abnormal $Q$ waves in the inferior limb leads. The other patients in this group had chronic stable angina. All the patients with previous myocardial infarction in both groups had had successful coronary angioplasty or thrombolytic therapy during the acute phase, and demonstrated preserved left ventricular wall motion in the chronic phase. Thus no patient in the study had an akinetic or dyskinetic wall segment in the territory of the coronary artery that was to be dilated in this study. Heart rate did not change during the procedure: $74.3(6.71)$ (range $59-85)$ at baseline to $72.4(7.51)(60-85)$ beats/min during angioplasty in the LAD group and from 69.5 $(9.80)(51-85)$ at baseline to $67.6(9.69)$ (54-80) beats/min during angioplasty in the LC group (both NS).

\section{ST SHIFT ON INTRACORONARY AND} PRECORDIAL ECGS

ST segment changes were apparent on the intracoronary ECG during angioplasty in all but one of the study patients: one showed ST segment depression and the other 38 ST elevation. The degree of ST segment change from baseline to angioplasty was greater in the LC group $(16.4(11.3) \mathrm{mm})$ than in the LAD group $(8.32(4.02) \mathrm{mm})(\mathrm{P}<0.01)$.

For the body surface precordial leads, the ST segment shifted in all patients in the LAD group (21 elevated and one depressed). In the LC group 10 patients presented with negative ST segment shifts in the right precordial leads. Three showed positive shifts in the lateral precordial leads and in five there was no remarkable ST segment shift.

PROJECTION INDEX OF ST SEGMENT The projection index of the ST segment was 
Table 2 continued

\begin{tabular}{|c|c|c|c|c|c|}
\hline \multicolumn{2}{|c|}{$I c-E C G S T$ shift } & \multicolumn{3}{|l|}{$B s-E C G m x S T$ shift } & \multirow[b]{2}{*}{ Projection index of $S T$ shift } \\
\hline Before (mm) & During (mm) & Lead & Before $(\mathrm{mm})$ & During ( $\mathrm{mm})$ & \\
\hline $\begin{array}{c}-3 \\
0 \\
1 \cdot 5 \\
4 \\
1 \\
-5 \\
1\end{array}$ & $\begin{array}{r}-3 \\
7 \\
35 \\
21 \\
19 \\
24 \\
10\end{array}$ & $\begin{array}{l}\text { No remarkable change } \\
\text { No remarkable change } \\
\text { V5 } \\
\text { V5 } \\
\text { V1 } \\
\text { V3 } \\
\text { V3 }\end{array}$ & $\begin{array}{c}-0.5 \\
0 \\
0 \\
2 \\
-0.5\end{array}$ & $\begin{array}{c}1.5 \\
1.5 \\
-2 \\
0 \\
-2\end{array}$ & $\begin{array}{l}0 \\
0 \\
0.06 \\
0.09 \\
0 \cdot 11 \\
0.07 \\
0.06\end{array}$ \\
\hline $\begin{array}{l}0 \\
6 \\
0\end{array}$ & $\begin{array}{r}7 \\
24 \\
13\end{array}$ & $\begin{array}{l}\text { No remarkable change } \\
\text { V3 } \\
\text { V2 }\end{array}$ & $\begin{array}{l}0 \\
0.5\end{array}$ & $\begin{array}{l}-1 \\
-1\end{array}$ & $\begin{array}{l}0 \\
0.06 \\
0.07\end{array}$ \\
\hline $\begin{array}{r}-3 \\
3 \\
0 \\
1 \\
0 \\
3 \\
0 \\
-2\end{array}$ & $\begin{array}{l}17 \cdot 5 \\
12 \\
18 \\
8 \\
17 \\
15 \\
48 \\
10\end{array}$ & $\begin{array}{l}\text { No remarkable change } \\
\text { No remarkable change } \\
\text { V2 } \\
\text { V3 } \\
\text { V3 } \\
\text { V3 } \\
\text { V2 } \\
\text { V5 }\end{array}$ & $\begin{array}{l}1 \\
0 \\
0 \\
0 \\
1 \\
0\end{array}$ & $\begin{array}{l}-1 \\
-1 \\
-1 \\
-1 \\
-1.5 \\
1.5\end{array}$ & $\begin{array}{l}0 \\
0 \\
0 \cdot 11 \\
0 \cdot 14 \\
0.06 \\
0.08 \\
0.05 \\
0 \cdot 13\end{array}$ \\
\hline
\end{tabular}

significantly greater in the LAD group $(0.42$ $(0 \cdot 20)$, range 0.16 to 0.88$)$ than in the LC group $(0.06(0.05)$, range 0 to 0.14$)(P<$ $0.001)$.

U WAVE CHANGES ON INTRACORONARY ECG The incidence of different patterns of U-wave changes between baseline and angioplasty conditions-that is, change to positivity, no change, change to negativity, and biphasic Uwave change-was similar in the LAD and LC groups $(23 \%$ v 39\%; $23 \%$ v $17 \%$; $41 \%$ v $44 \%$; $13 \% v 0 \%$, respectively). Table 3 summarises

Table 3 Changes of $U$ wave amplitude in intracoronary ECGs during angioplasty of the $L A D$ or LC coronary arteries

\begin{tabular}{|c|c|c|c|}
\hline \multirow[b]{2}{*}{ Subgroup (n) } & \multicolumn{3}{|c|}{ U wave amplitude ( $\mathrm{mm}$ ) } \\
\hline & Baseline & During angioplasty & Pvalue \\
\hline \multicolumn{4}{|l|}{ LAD group: } \\
\hline Positivity (5) & $\begin{array}{l}0 \cdot 20(1 \cdot 30) \\
(-2-1)\end{array}$ & $\begin{array}{l}2 \cdot 30(0.97) \\
(1.5-4)\end{array}$ & $<0.1$ \\
\hline Unchanged (5) & $\begin{array}{l}1 \cdot 10(0 \cdot 74) \\
(0-2)\end{array}$ & $\begin{array}{l}1 \cdot 10(0 \cdot 74) \\
(0-2)\end{array}$ & NS \\
\hline Negativity (9) & $\begin{array}{l}0 \cdot 78(1 \cdot 09) \\
(-1-2)\end{array}$ & $\begin{array}{l}-1.5(0.61) \\
(-0.5--2.5)\end{array}$ & $<0.001$ \\
\hline \multicolumn{4}{|l|}{ LC group: } \\
\hline Positivity (7) & $\begin{array}{l}-0.64(1.80) \\
(-3-1.5)\end{array}$ & $\begin{array}{l}1.93(1 \cdot 79) \\
(0-5)\end{array}$ & $<0.05$ \\
\hline Unchanged (3) & $\begin{array}{l}1 \cdot 83(0 \cdot 29) \\
(1 \cdot 5-2)\end{array}$ & $\begin{array}{l}1 \cdot 83(0 \cdot 29) \\
(1 \cdot 5-2)\end{array}$ & NS \\
\hline Negativity (8) & $\begin{array}{l}1 \cdot 58(1 \cdot 75) \\
(-1 \cdot 5-4)\end{array}$ & $\begin{array}{l}-0.56(1.29) \\
(-2-1.5)\end{array}$ & $<0.01$ \\
\hline
\end{tabular}

All data are expressed as mean (SD) (range).

ECG, electrocardiogram; LAD, left anterior descending; LC, left circumflex.

Data for patients with biphasic U waves at baseline or during angioplasty are not shown.

Table 4 Reflection of $U$ waves in the intracoronary ECGs on body surface precordial $E C G$ during angioplasty of the $L A D$ or $L C$ coronary arteries

\begin{tabular}{lllll}
\hline \multirow{2}{*}{$\begin{array}{l}\text { Intracoronary } \\
(n)\end{array}$} & \multicolumn{3}{l}{ Body surface precordial leads } \\
\cline { 2 - 5 } & Positivity & Unchanged & Negativity & Mixed \\
\hline LAD group: & & & & \\
$\quad$ Positivity (5) & 4 & 1 & 0 & 0 \\
$\quad$ Unchanged (5) & 0 & 4 & 1 & 0 \\
Negativity (9) & 0 & 4 & 5 & 0 \\
$\quad$ Biphasic (3) & 0 & 1 & 0 & 2 \\
Total & 4 & 6 & 6 & 2 \\
LC group: & 0 & 3 & 1 & 0 \\
$\quad$ Positivity (7) & 0 & 4 & 0 & 0 \\
Unchanged (3) & 3 & 13 & 2 & 0 \\
Negativity (8) & 3 & &
\end{tabular}

See footnote to table 3 for abbreviations. the changes in $\mathrm{U}$-wave amplitude between baseline and coronary occlusion.

\section{COMPARISON OF DETECTION OF U-WAVE} CHANGES BY INTRACORONARY AND SURFACE ECGS

U-wave changes during angioplasty were observed more frequently on the intracoronary ECG than on the surface precordial ECG in both groups (intracoronary ECG $v$ precordial ECG: $17(77 \%) v 12(55 \%)$ out of $22 \mathrm{LAD}$ patients (NS) and $15(83 \%) v 5(28 \%)$ out of 18 LC patients $(P<0.01)$ ). In only one patient (case 10 in table 1) was the surface precordial ECG more sensitive than the intracoronary ECG in detecting a U-wave change between baseline and angioplasty conditions.

\section{REFLECTION OF EPICARDIAL U-WAVE CHANGES} IN PRECORDIAL ECG

The relations between $U$-wave changes in the intracoronary and surface precordial ECGs are shown in table 4 . In the LAD group, out of the 14 patients who showed $U$-wave changes in a positive (cases 1 to 5) or negative (cases 11 to 19) direction on the intracoronary ECG, nine (64\%) showed similar changes in the body surface precordial lead ECGs. Figures $2 \mathrm{~A}$ and 2B show examples of the positive (case 5, table 1) and negative (case 16) subgroups. Two of the three patients who showed biphasic epicardial $U$ waves during the procedure showed mixed changes in the body surface ECG. An illustrative example of such a patient (case 22) is shown in fig 2C. There were no discrepancies between U-wave changes in the intracoronary and surface precordial ECGs in the LAD group.

Of the 15 patients in the LC group with Uwave changes in their intracoronary ECGs, only five (33\%) also showed U-wave changes in their surface precordial ECGs. In one patient a positive change in the epicardial Uwave was accompanied by a negative $U$-wave change in the body surface right precordial ECG (case 7, table 2) (fig 3A). Three patients with negative epicardial U-wave changes pre- 
A

a

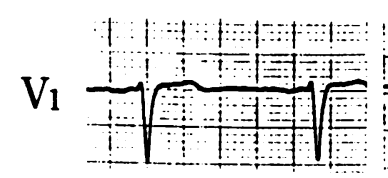

$\mathrm{V}_{2}$
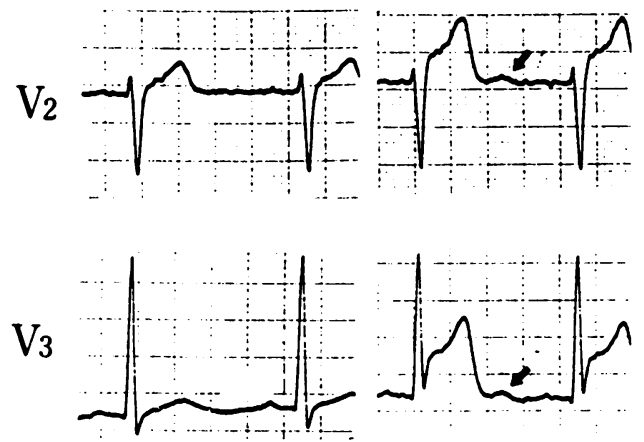

b
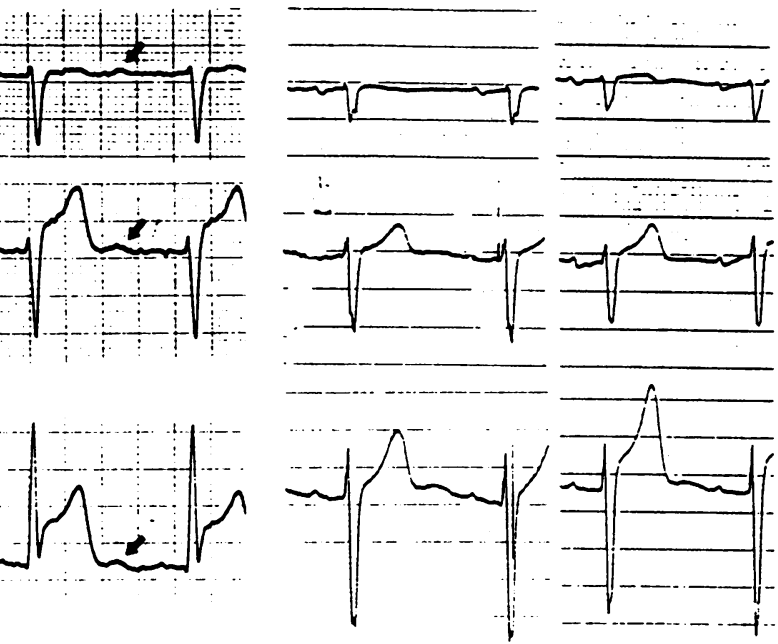

$\mathrm{V}_{4}$
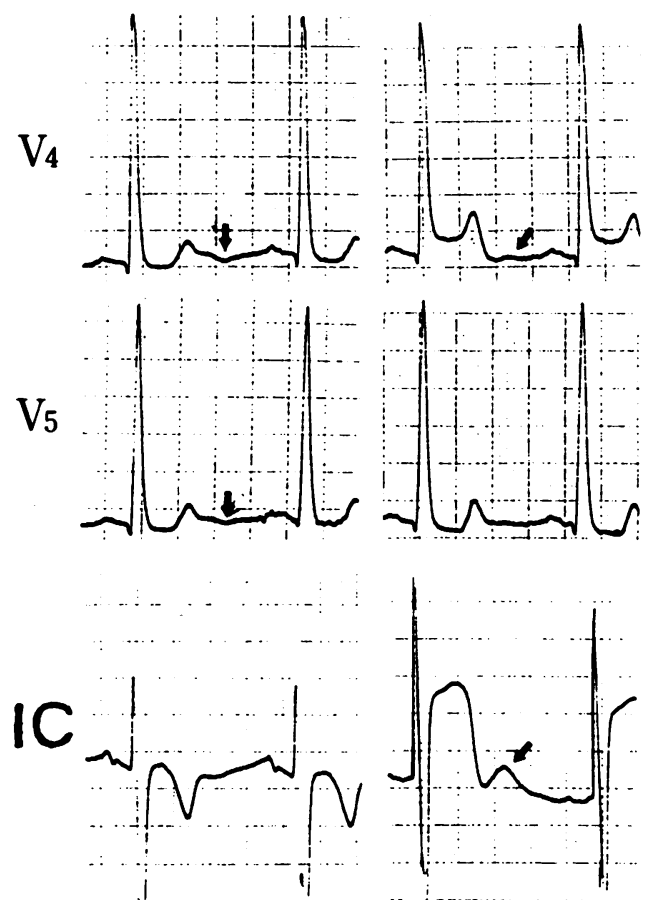

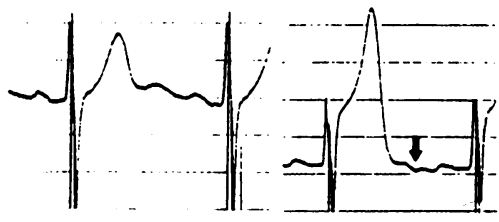

B

a
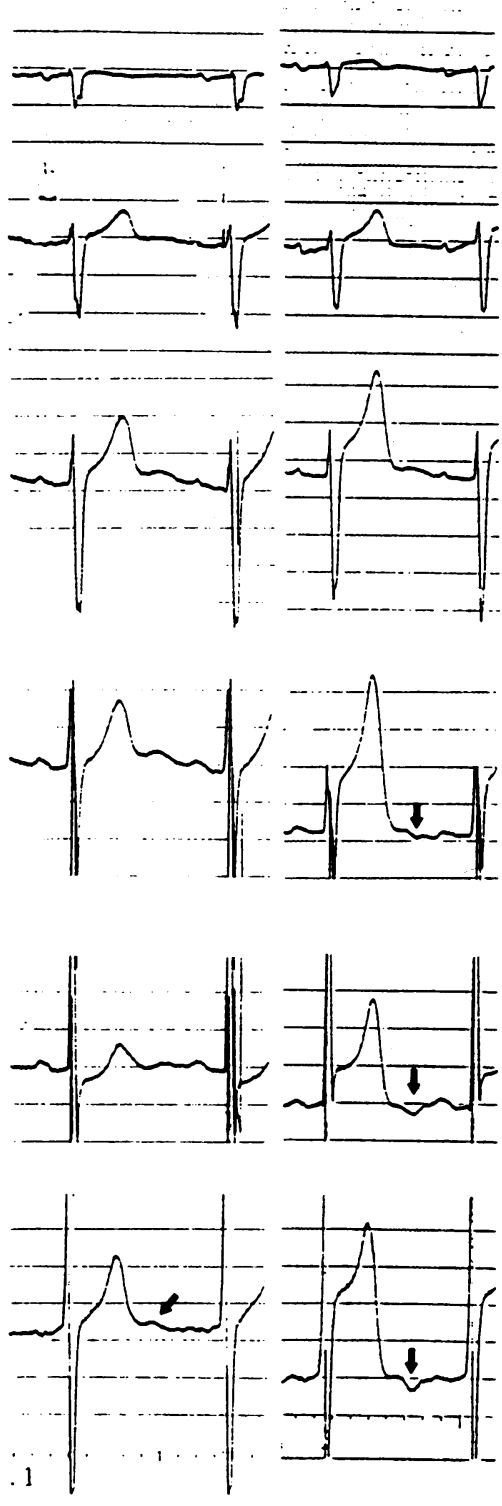

C
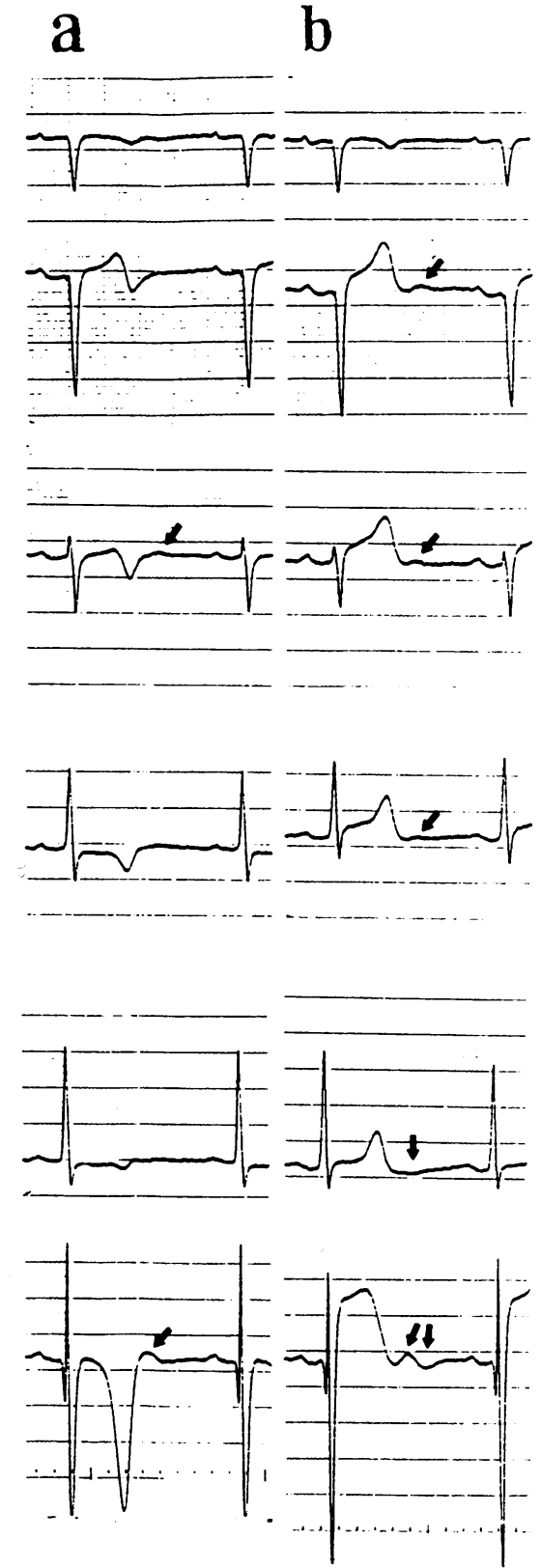

Figure 2 Representative examples of simultaneous recordings of intracoronary (IC) and body surface precordial ECGs under baseline conditions (a) and during coronary angioplasty (b) in the LAD group. Arrow indicates $U$ wave. (A) recording from case 5 . At baseline the $U$ wave on the intracoronary $E C G$ is flat and $U$ wave in the precordial V4 and V5 leads is negative. During angioplasty a positive $U$ wave can be seen in the intracoronary ECG with simultaneous $U$ wave positivity in precordial leads V1 to V4 of the body surface ECG. (B) Recording from case 16 . At baseline $U$ waves in the

intracoronary and precordial ECGs are positive. During angioplasty negative $U$ waves are apparent in both the intracoronary and body surface precordial (V4 and V5 leads) ECGs. (C) Recording from case 22 of the $L A D$ group. At baseline the $U$ wave on the intracoronary ECG is positive and the $U$ wave in the body surface precordial V3 lead ECG is slightly positive. During angioplasty the $U$ wave in the intracoronary ECG changes to a biphasic appearance, and positive $U$ waves appear in precordial leads V2 to V4 with a negative $U$ wave in the V5 lead.

sented with right to central positive precordial U-wave changes (cases 15-17, table 2). An illustrative ECG from such a patient (case 16) is shown in fig 3B. Reciprocal projection of the $\mathrm{U}$-wave change from the ischaemic inferoposterior myocardium to the anterior precordial leads of the body surface ECG is a possibility in these four LC patients who showed different U-wave changes in their intracoronary and surface precordial ECGs. In another patient (case 18, table 2), a U-wave change similar to those observed in intracoronary ECGs (that is, in the negative direction) appeared in the lateral precordial ECG. This was regarded as a primary change, reflecting myocardial ischaemia in the lateral wall of the left ventricle supplied by the LC coronary artery.

\section{Discussion}

Jain et al first described epicardial U-wave changes during angioplasty-induced myocardial ischaemia in humans, ${ }^{14}$ but they did not analyse the epicardial U-wave changes in detail and they did not examine how these changes were reflected in the body surface ECG. The present study provides new information regarding these questions in a small but well-characterised group of patients undergoing percutaneous transluminal coro- 
A

a

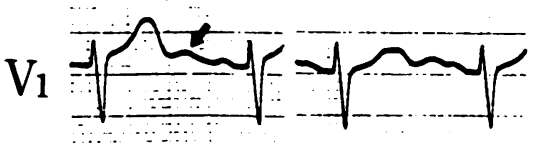

$\mathrm{V}_{2}$
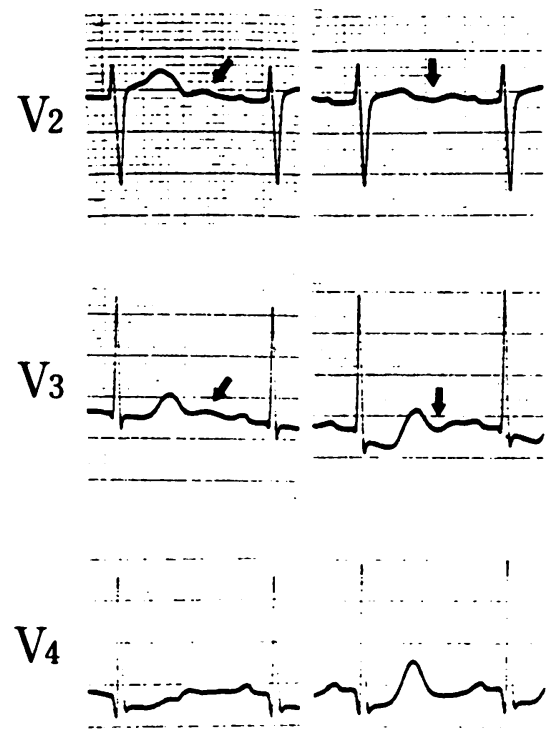

$\mathrm{V}_{5}$

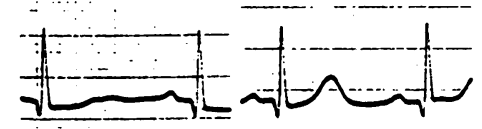

IC

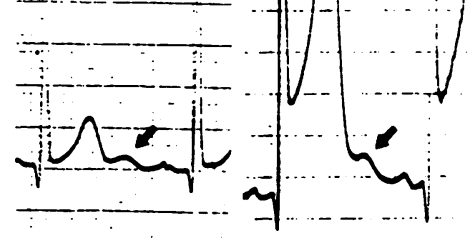

B

a

b
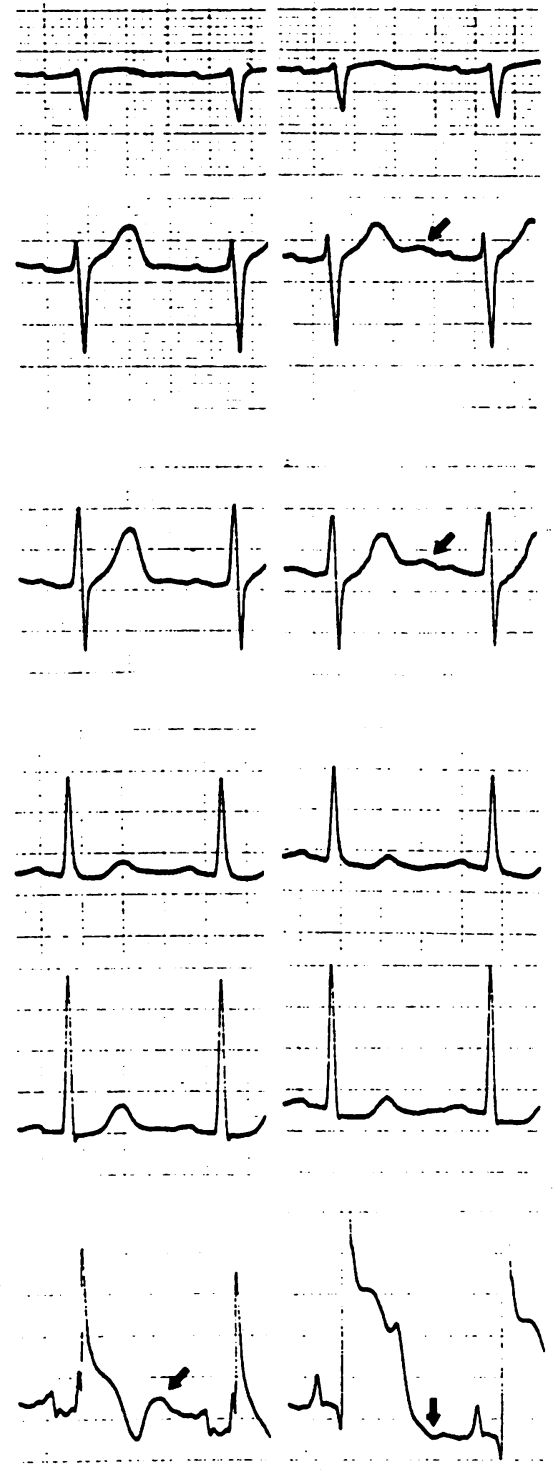

C
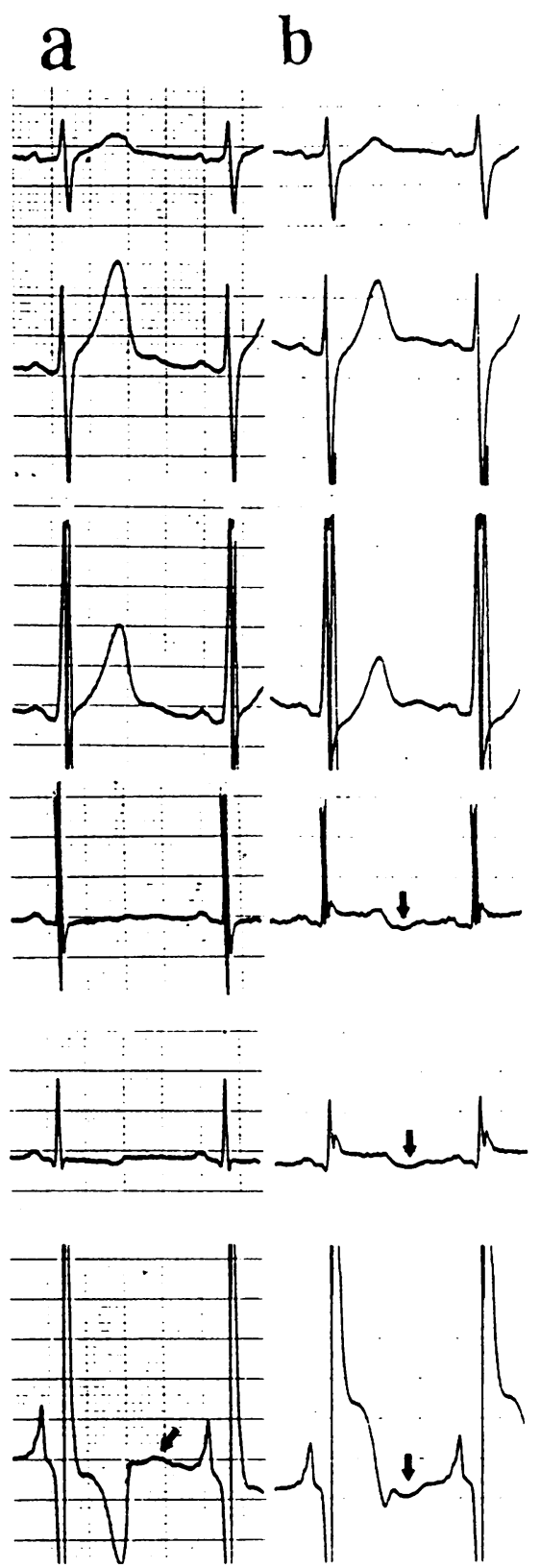

Figure 3 Representative examples of intracoronary (IC) and body surface precordial ECGs from the LC group under baseline conditions (a) and during coronary occlusion (b). (A) Recording from case 7 of the LC group. At baseline the U waves on the intracoronary and surface precordial (V1 to V3 leads) ECGs are positive. During angioplasty the amplitude of the $U$ wave in the intracoronary ECG becomes more positive. Conversely, negative $U$ waves appear in ECGs of right precordial leads V2 and V3. (B) Recording from case 16. At baseline the $U$ wave in the intracoronary ECG is positive, and that in the body surface precordial leads is flat. During angioplasty the intracoronary ECG $U$ wave becomes negative. Conversely, positive $U$ waves appear in precordial leads V2 and V3 of the body surface ECG. (C) Recording from case 18 . At baseline the $U$ wave in the intracoronary ECG is positive. During coronary occlusion negative U waves appear both on the intracoronary ECG and lateral precordial ECG (V4 and V5 leads).

nary angioplasty of the LAD or LC coronary artery.

INTRACORONARY ECG AND SUBJECT SELECTION $U$ waves on the body surface ECG are often difficult to assess because of their small deflections, especially when limb leads rather than precordial leads are used. In contrast, as shown in this study, the amplitude of $U$ waves recorded in intracoronary ECGs is large enough to be analysed quantitatively, giving important information on changes in epicardial U-waves in response to myocardial ischaemia. The interpretation of $U$ waves recorded on the intracoronary ECG is, how- ever, not well understood, but this technique is likely to sample the average U-wave deflection of a wide area of ventricular epicardium because the contact electrode is long. Recordings of intracoronary ECGs in the beating heart are often unstable presumably because of the motion of the electrode relative to the heart. In addition, even when adequate recordings have been obtained, recognition of $\mathrm{U}$ waves has often been prevented by tachycardia, difficulty in determining the QT segment, and T-U wave fusion. In this study, data from about a third of the patients was discarded for these reasons. Thus the subjects of this study were carefully selected in order to 
characterise accurately the epicardial U-wave changes and their relation to surface precordial ECGs.

\section{EPICARDIAL U-WAVE CHANGES DURING} MYOCARDIAL ISCHAEMIA

Until recently, no data on epicardial U-wave changes during myocardial ischaemia in humans had been available. However, when Jain et $a l^{14}$ examined epicardial U-wave changes in intracoronary ECGs during coronary angioplasty they concluded that negative U-waves in the intracoronary ECG are not specific for ischaemia in the area supplied by the LAD or left main coronary arteries. They further suggested that the development of new positive U-waves was also a marker of myocardial ischaemia. Our data confirm these observations. We were able to carry out quantitative assessment of $\mathrm{U}$-waves in intracoronary ECGs, and distinguished four patterns of Uwave change that developed from baseline to fully developed myocardial ischaemia during angioplasty: (1) change to positivity (including a new positive U-wave), (2) unchanged, (3) change to negativity (including a new negative U-wave), and (4) a biphasic U-wave at baseline or during coronary occlusion. The incidence of $U$-wave changes to positivity or negativity was similar in our patients undergoing angioplasty of the LAD and LC coronary arteries. Until recently, little attention has been paid to positive U-wave changes during myocardial ischaemia probably because it is difficult to distinguish between abnormal positive $U$ waves and the ubiquitous positive $U$ waves observed in healthy subjects. Further studies are needed to clarify the clinical significance of positive $U$ waves occurring during myocardial ischaemia.

\section{COMPARISON BETWEEN INTRACORONARY AND PRECORDIAL ECGS FOR DETECTING U-WAVE CHANGES}

No previous studies have investigated whether the intracoronary ECG using a unipolar single lead is better than the body surface ECG using multiple leads for identifying $U$-wave changes during myocardial ischaemia, although many such studies have been done on ST segment shifts. ${ }^{15-17}$ The two methods may have different capabilities for characterising U-wave changes during myocardial ischaemia; intracoronary ECGs might be better for obtaining adequate U-waves for precise analysis, whereas body surface ECGs might be better for detecting non-homogeneous $U$-wave changes over the ischaemic myocardium. In the patients we studied an intracoronary ECG was more sensitive for detecting $U$-wave changes during myocardial ischaemia than a surface precordial ECG. The same result was found when data from intracoronary ECGs were compared with data from limb leads (unpublished observations). These findings accord with similar studies on ST segment changes. ${ }^{15-17}$ The inaccuracy of body surface precordial ECGs in detecting $\mathrm{U}$-wave changes in patients undergoing angioplasty of the LC coronary artery is most probably explained by ineffective posi- tioning of the ECG leads in relation to the ischaemic myocardium or by the long distance between the inferoposterior wall and the recording electrode. ${ }^{21}$ This was indirectly verified by the low ST projection index of the present patient group. In patients undergoing angioplasty of the LAD coronary artery, it seems that multiple precordial leads are appropriate for detecting anterior myocardial ischaemia. ${ }^{17}$ This was supported by relatively high ST projection index in this subgroup. However, even in this subgroup, detection of U-wave changes by body surface ECGs using multiple precordial leads was also inadequate compared with the intracoronary ECG. It is thought that the smaller change in amplitude of the $U$ wave relative to the ST segment made reading of the $U$-wave change difficult on the body surface ECG when the change was projected from the epicardium.

\section{PROJECTION OF EPICARDIAL U WAVES TO} PRECORDIAL ECG

The association between $U$-wave changes in epicardial and body surface ECGs in humans remains unclear. The present study showed that primary $\mathrm{U}$-wave change-that is, the same as that recorded on the intracoronary ECG-appeared in the surface precordial ECG in many patients undergoing angioplasty of the LAD coronary artery, but only rarely in patients undergoing angioplasty of the LC coronary artery. A more important finding in this study was that reciprocal U-wave changes sometimes occur in the right to central surface precordial leads in inferoposterior myocardial ischaemia. This observation supports the hypothesis recently proposed by Hasegawa et $a l^{11-13}$ that prominent positive exercise-induced $\mathrm{U}$-waves in the right precordial leads are reciprocal changes corresponding to the inverted U-wave originating from the inferoposterior myocardial ischaemia. Hasegawa et al described only the precordial reciprocal Uwave change to positivity,,$^{11-13}$ but the present study is the first to document the precordial reciprocal negative U-wave change in inferoposterior myocardial ischaemia: this phenomenon probably occurs only very rarely. Projection of $\mathrm{U}$-wave changes from the inferoposterior myocardium thus affects the amplitude and polarity of surface precordial U-waves, as is the case for other ECG components including the QRS complex, ST segment, and $T$ wave..$^{22-28}$

\section{CLINICAL IMPLICATIONS}

Not only negative but also positive epicardial U-wave change occurs in response to ischaemia in both the anterior and posterior myocardium. Correlation of epicardial and surface precordial $U$-wave changes in this study provided fundamental information on the nature of U-wave changes in surface precordial ECGs during myocardial ischaemia. It was noteworthy that as well as the primary Uwave changes observed in anterior myocardial ischaemia, reciprocal $U$-wave changes could be relatively prominent on the body surface precordial ECG in selected cases of posterior 
myocardial ischaemia. Observations by Jain et $a l^{14}$ and our present study showed a lack of specificity of the epicardial negative U-wave for anterior myocardial ischaemia, although our results do not negate the established clinical significance of negative $U$ waves in body surface precordial ECGs as a highly specific marker for anterior myocardial ischaemia. In the present study, when ischaemia-induced Uwave inversion was defined as the new appearance of a negative $U$ wave or an increase in negativity, LAD occlusion induced negative $U$ waves in body surface precordial ECGs in seven of $22 \mathrm{LAD}$ patients and LC occlusion did so in two of 18 LC patients, yielding a high specificity $(89 \%)$ and moderate sensitivity (34\%) of this feature for diagnosing anterior myocardial ischaemia. It appears that the rare occurrence of reciprocal negative or primary negative $U$-wave change in the surface precordial ECG in inferior myocardial ischaemia does not reduce the specificity of precordial negative $U$ wave for diagnosing anterior myocardial ischaemia. The significance of Uwave changes in the epicardial ECG or body surface ECG should be evaluated separately.

\section{STUDY LIMITATIONS}

We studied too few patients to reach firm conclusions. Intracoronary ECGs using a single lead cannot represent $U$-wave changes over the entire ischaemic myocardium because $U$ waves under such conditions are not homogeneous, as suggested by an earlier experimental study. ${ }^{29}$ We cannot extrapolate from this study on myocardial ischaemia caused by angioplasty-induced coronary occlusion to ischaemia induced by exercise because the pathophysiology is completely different in these two situations (reduction of flow $v$ increase of demand).

1 Palmer JH. Isolated $\mathrm{U}$ wave negativity. Circulation 1953;7:205-10.

2 Lepeschkin E. The U wave of the electrocardiogram. Mod Concepts Cardiovasc Dis 1969;38:39-45.

3 Gerson MC, Phillips JF, Morris SN, McHenry PL. Exercise-induced U-wave inversion as a marker of stenosis of the left anterior descending coronary artery. Circulation 1979;60:1014-20.

4 Gerson MC, McHenry PL. Resting U wave inversion as a marker of stenosis of the left anterior descending coronary artery. $A m$ F Med 1980;69:545-50

5 Kishida H, Cole JS, Surawicz B. Negative U wave: a highly specific but poorly understood sign of heart disease. $A m \mathcal{F}$ Cardiol 1982;49:2030-6.

6 Miwa K, Murakami T, Kambara H, Kawai C. U wave inversion during attacks of variant angina. Br Heart $\mathcal{f}$ $1983 ; 50: 378-82$

7 Matsuguchi T, Koiwaya Y, Nakagaki O, Takeshita A, Nakamura M. Transient U wave inversion during variant angina. Am Heart $\mathcal{F}$ 1984;108:899-904.
8 Yano H, Hiasa Y, Aihara T, Nakaya Y, Mori H. Inverted U wave in ergonovine-induced vasospastic angina. Clin Cardiol 1987;10:633-9.

9 Yamakado T, Nakano T, Masuda T, Takezawa H. Coronary angiographic findings associated with $\mathrm{U}$-wave inversion during coronary artery spasm. Am $f$ Cardiol 1987;60:188-90

10 Yano H, Hiasa Y, Aihara T, Nakaya Y, Mori H. Negative U wave during percutaneous transluminal coronary angioplasty. Clin Cardiol 1991;14:232-6.

11 Hasegawa $K$, Nezuo $S$, Fujiwara $T$, Samukawa $M$ Tadaoka S, Nakao $M$, et al. Transient positive $U$ wave as a new marker of the critical left circumflex artery stenosis and postero-inferior ischemia [in Japanese]. Heart 1988; and postero- $269-75$.

12 Hasegawa K, Fujiwara T, Sawayama T, Nezuo S, Nakao $M$, Tadaoka $S$, et al. Angina-induced transient positive $U$ wave in right precordial leads: a marker of left circumflex artery/right coronary artery stenosis [in Japanese]. Heart 1988;20:1033-9.

13 Chikamori T, Yamada M, Takata J, Furuno T, Yamasaki F, Doi YL. Exercise-induced prominent $U$ waves as a marker of significant narrowing of the left circumflex or right coronary artery. Am 7 Cardiol 1994;74:495-9.

14 Jain A, Jenkins MG, Gettes LS. Lack of specificity of new negative $U$ waves for anterior myocardial ischemia as evidenced by intracoronary electrogram during balloon angioplasty. $₹ \mathrm{Am}$ Coll Cardiol 1990;15:1007-11.

15 Friedman PL, Shook TL, Kirshenbaum JM, Selwyn AP, Ganz P. Value of the intracoronary electrocardiogram to monitor myocardial ischemia during percutaneous transluminal coronary angioplasty. Circulation 1986;74:330-9.

16 Taggart $P$, Sutton $P$, John R, Hayward R, Swanton H. The epicardial electrogram: a quantitative assessment during balloon angioplasty incorporating monophasic action potential recordings. Br Heart 7 1989;62:342-52.

17 Berry C, Zalewski A, Kovach R, Savage M, Goldberg S. Surface electrocardiogram in the detection of transmural myocardial ischemia during coronary artery occlusion. Am f Cardiol 1989;63:21-6.

18 AHA Committee Report. A reporting system on patients evaluated for coronary artery disease. Circulation 1975;51 (suppl):5-40

19 Rezkalla S, Moushmoush B, Connors BC, Turi ZG. Monitoring of ischemia during percutaneous coronary angioplasty: influence of guidewire, balloon placement, and lead selection. Cathet Cardiovasc Diagn 1988;15: 233-6.

20 Surawicz B, Kemp RL, Bellet S. Polarity and amplitude of the $U$ wave of the electrocardiogram in relation to that of the T wave Circulation 1957;15:90-7.

21 Spach MS, Barr RC, Lanning CF, Tucek PC. Origin of body surface QRS and T wave potentials from epicardial body surface QRS and T wave potentials from epicardial potential distributions in

22 Schamroth L, Perlman MM. The electrocardiographic manifestations of acute true posterior myocardial infarction. Heart Lung 1972;1:658-60.

23 Bough EW, Korr KS. Prevalence and severity of circumflex coronary artery disease in electrocardiographic posterior myocardial infarction. $7 \mathrm{Am}$ Coll Cardiol 1986;7:990-6.

24 Sclarovsky S, Topaz O, Rechavia E, Strasberg B, Agmon J. Ischemic ST segment depression in leads $V_{2}-V_{3}$ as the presenting electrocardiographic feature of posterolateral wall myocardial infarction. Am Heart $\mathcal{f}$ 1987;113: wall myocar

25 Boden WE, Spodick DH. Diagnostic significance of precordial ST-segment depression (editorial). Am $\mathcal{f}$ Cardiol 1989;63:358-61.

26 Kataoka H, Tamura A, Mikuriya Y. Central precordial reciprocal ST-segment elevation in posterolateral myocardial infarction. Am Heart $\mathcal{F}$ 1993;125:1202-4.

27 Eisenstein I, Sanmarco ME, Madrid WL, Selvester RH. Electrocardiographic and vectorcardiographic diagnosis of posterior wall myocardial infarction: significance of the T wave. Chest 1985;88:409-16.

28 Kataoka $\mathrm{H}$. Relation of $\mathrm{T}$-wave polarity in precordial $\mathrm{V}_{1}$ lead to right or left circumflex coronary pathoanatomy in acute inferior myocardial infarction. Chest 1994;105: 360-3.

29 Fu LT, Kato N, Takahashi N. Ischaemia-induced negative $\mathrm{U}$ waves in electrocardiograms: an experimental study in canine hearts. Cardiovasc Res 1982;16:240-8. 